\title{
Analysis of the seismic bearing capacity of shallow foundations
}

\author{
Análisis de la Capacidad de Soporte Sísmica de Fundaciones Superficiales
}

Juan Carlos Tiznado A. (Main and Contact Author)

\section{School of Engineering}

Universidad Andres Bello

juan.tiznado@unab.cl

Avenida República 237

CP 8370146, Santiago, Chile.

\section{Resumen}

En el contexto de la práctica ingenieril, el problema de la capacidad de soporte sísmica de fundaciones superficiales generalmente ha sido resuelto, de modo indirecto, ya sea considerando un incremento en las tensiones admisibles estáticas del suelo, asociado a la probabilidad de ocurrencia de un cierto evento sísmico de diseño, o bien adoptando un enfoque de tipo pseudoestático equivalente. Sin embargo, durante las últimas décadas se han desarrollado una serie de métodos analíticos que abordan directamente el problema desde el punto de vista sísmico. Este artículo presenta un análisis comparativo de tipo paramétrico entre diferentes métodos para estimar la capacidad de soporte sísmica de fundaciones superficiales corridas. Se consideraron métodos analíticos, desarrollados en el contexto de las teorías de equilibrio límite y análisis límite, y también procedimientos de diseño simplificados típicamente utilizados en la práctica. Los resultados obtenidos muestran un importante deterioro de la capacidad de soporte de la fundación en la medida que la aceleración máxima del sismo aumenta, lo cual pone de manifiesto la necesidad de establecer una medida de la confiabilidad asociada a los métodos de cálculo y factores de seguridad comúnmente usados para diseño sísmico.

Palabras clave: Capacidad de soporte sísmica, fundaciones superficiales, terremotos, métodos analíticos, métodos prácticos.

\section{Introduction}

The bearing capacity of foundations under static loads has been an extensively studied topic in soil mechanics. On the basis of the works of Prandtl (1921) and Terzaghi (1943), several researchers (Caquot \& Kerisel, 1953; Meyerhof, 1963; Hansen, 1970; Vesic, 1973; among others) have developed theories for estimating the load capacity of shallow foundations, considering the influence of geometry, embedment depth, and eccentricity and inclination of loads. Despite the inherent limitations of these theories (Bowles, 1996; Lee \& Salgado, 2005), they have been successfully used by geotechnical and foundation engineers for many years. However, the problem of the seismic bearing capacity of shallow foundations is far from being considered solved.

The first studies related to the seismic effect on the bearing capacity were those carried out by Meyerhof $(1951 ; 1953)$ and Shinohara et al. (1960), who adopted a pseudo-static approach. By applying horizontal and vertical accelerations to the center of gravity of the structure, the problem is reduced to a static case of bearing capacity with inclined and eccentric loads (Soubra, 1999). Nevertheless, in these methods the inertial effects on the soil mass beneath the foundation are not considered and this could have important effects on the overall system response (Sarma \& lossifelis, 1990; Soubra, 1999; CEN Eurocode 8, 2004).

Subsequently, researchers such as Sarma \& lossifelis (1990), Richards et al. (1993), Budhu \& Al-Karni (1993), Kumar \&
Danilo Paillao V.

Knight Piésold Consulting, Chile

dpaillao@knightpiesold.com

\author{
Manuscript Code: 0365 \\ Date of reception/acceptation: 01jan2014/01aug2014
}

\begin{abstract}
In the context of engineering practice, the problem of the seismic bearing capacity of shallow foundations has been solved indirectly, either due an increase of the static allowable soil pressures related to the probability of occurrence of the design earthquake or by adopting an equivalent pseudo-static approach. However, during last decades, a series of analytical methods that directly address the problem from the seismic point of view has been developed. This paper presents a parametric comparative analysis of different methods for estimating seismic bearing capacity of shallow strip foundations. Analytical methods, developed in the framework of both limit equilibrium and limit analysis theories, and also simplified design procedures typically used in practice were considered. The results obtained show an important decrease of the bearing foundation capacity with increasing of the maximum earthquake acceleration, which highlights the need to obtain a measure of the reliability associated with both calculation methods and safety factors commonly used for seismic design.
\end{abstract}

Keywords: Seismic bearing capacity; shallow foundations; earthquakes; analytical methods; practical methods.
Kumar (2003) and Choudhury \& Subba Rao (2005) have studied the problem of the seismic bearing capacity of shallow strip foundations under vertical loads by using limit equilibrium and considering the inertia effects in both soil and structure. Nonetheless, it is well known that the limit equilibrium method provides solutions which cannot be said to be an upper or a lower-bound one with respect to the exact solution (Soubra, 1997); mainly because this method neglects the stress-strain relationship of the soil and, according to the mechanics of solids, this condition must be satisfied for a complete solution (Chen \& Scawthorn, 1970). For this reason, authors such as Dormieux \& Pecker (1995), Paolucci \& Pecker (1997), Soubra (1997; 1999), Zhu (2000) and Ghosh (2008) have addressed this problem in a more rigorously way by using the upper bound theorem of limit analysis theory (Chen \& Scawthorn, 1970; Chen, 1975) for an associated flow rule Mohr-Coulomb material. It has allowed obtaining a series of upper envelopes of the exact solution and thus establishing a comparison between the different existing theories. Moreover, during last years the problem of seismic bearing capacity of foundations on slopes or near to them has received attention (Choudhury \& Subba Rao, 2006; Yang, 2009; Castelli \& Motta 2010; Saada et al., 2011; Farzaneh et al., 2013). However, it has to be mentioned that, although the solutions obtained by using the upper bound theorem of limit analysis theory are rigorous ones and allows limiting the exact solution, they correspond, in general, to an unsafe estimate of the failure load. For this reason, at present the efforts are aimed to improve the existing solutions available in the literature. 
Estimation of the seismic bearing capacity of shallow foundations

\section{Traditional approaches}

In the context of engineering practice, one of the traditional ways in which the seismic design of shallow foundations has been addressed consists in increasing the allowable bearing capacity of soil derived for the static case (for a minimum factor of safety of 3.0) by percentages ranging from $20 \%$ to $50 \%$ (33\% is commonly used for most cases). This mentioned increase of the allowable soil pressures is directly related to the probability of occurrence of the design earthquake. This can be interpreted as a reduction of the factor of safety used when earthquake loads in addition to static loads are used in design of the foundation (Puri \& Prakash, 2007). In this regard, Peck et al. (1974) suggests that, for foundations on clay, the factor of safety against failure of soil should not be less than 2.0 for extreme loads, which is equivalent to increase the static allowable soil pressures by a percentage of $50 \%$. On the other hand, some building codes in the United States (known as Model Building Codes) as, for example, the International Building Code (ICC IBC, 2012) permit adopting an increase of $33 \%$ in allowable bearing capacity of soil (rock, gravel, sand or clay) when load combinations include wind or seismic loads. According to Day (2006), this recommendation may be reasonable for dense granular soils, stiff to very stiff clays or hard bedrocks but is not applicable for friable rock, loose soils susceptible to liquefaction or pore water pressure increase, sensitive clays or clays likely to undergo plastic flow.

Another traditional way to address this problem consist in adopting an equivalent pseudo-static approach. The effects of both lateral and eccentric loads representing the seismic action are incorporated to the bearing capacity equations by using load inclination factors and effective footing dimensions. For this type of analysis, the general bearing capacity equations as proposed, for example, by Meyerhof (1963), Hansen (1970), or Vesic (1973) are commonly used, considering a minimum factor of safety against failure of soil of 2.0. However, as already mentioned, this type of methods has the limitation of disregarding the inertial effects on the soil-structure system.

Particularly, in Chile, the seismic design codes (INN NCh433:1996 Mod. 2009, 2009; INN NCh2369:2003, 2003) do not indicate how to estimate the bearing capacity of foundations. Nevertheless, the Highway Manual developed by the Ministry of Public Works (MOP Highway Manual, 2012) states that, for seismic design of foundations for bridges and related structures, provisions of Chapter 4 of the AASHTO Standard Specifications for Highway Bridges manual must be satisfied (AASHTO HB-17, 2002). This manual indicates that the ultimate bearing capacity of shallow foundations can be estimated using theoretical methods (general bearing capacity equations), semi-empirical methods (based on results of SPT or CPT tests), or plate load tests (ASTM D1194$72,1987)$. On the other hand, the foundation loads for use in a pseudo-static bearing capacity analysis of shallow foundations may be evaluated either by applying a pseudostatic load to the structure or from the results of a dynamic response analysis, in which case the reader is referred to the work of Lam \& Martin (1986) for guidance on the stiffness matrix method approach. Finally, for design verification, either Allowable Stress Design (ASD) method or Load and Resistance Factor Design (LRFD) method can be used. With the introduction of LRFD, it is intended to maintain the overall factor of safety for foundations at similar levels as the ones required by ASD (about 3.0 for static loads and about 2.0 for static plus seismic loads).

\section{Analytical methods}

Bearing capacity defines the load that a soil foundation can sustain at the state of incipient failure. In the static case, the bearing capacity $q_{\text {ult }}$ is usually calculated by superposition of the contributions from surcharge loading $q$, soil cohesion $c$, and soil unit weight $\gamma$. For shallow strip foundations under vertical central loading, Terzaghi (1943) proposed to use the following expression (Eq 1). Where $B$ is the width of the foundation and $N_{c}, N_{q}$ and $N_{\gamma}$ are the bearing capacity factors, that depend on the angle of internal friction $\phi$ of the soil.

$q_{u l t}=c N_{c}+q N_{q}+0.5 \gamma B N_{\gamma}$

The available analytical methods for estimating the seismic bearing capacity of shallow foundations, based on either limit equilibrium or limit analysis theories, have maintained the general form of equation (1), and thus have emphasized in both obtaining the bearing capacity factors for the seismic case and determining seismic $(E)$ to static $(S)$ bearing-capacity ratios. In general, to solve this problem these methods consider a foundation system under a vertical central load $P$ and a surcharge $q$ on the foundation level (the lateral passive resistance of the soil above this level is neglected). The seismic effect is considered (in a pseudo-static way) in both soil and structure by the inclusion of inertia forces (the base shear load, the inertia forces acting over the soil in motion, and the surcharge loading). The magnitude of these forces is related to the horizontal and vertical accelerations acting over the soil-foundation system ( $a_{h}$ and $a_{v}$, respectively). In pseudo-static analyses, these accelerations are commonly represented by seismic coefficients $k_{h}$ and $k_{v}$, expressed as a fraction of the acceleration of gravity $g$. (the vertical seismic coefficient is usually ignored). On the other hand, to formulate the equilibrium of forces and obtaining the seismic bearing capacity factors, these methods consider a certain failure mechanism composed of three zones: an elastic active zone (I), a transition zone (II), and a passive zone (III), such as occur in the static case (Figure 1a). However, the accelerations of a seismic event produce a non-symmetric failure mechanism, which is shallower than the static failure mechanism (Budhu \& Al-Karni, 1993). Some authors, such as Richards et al. (1993) consider a simplified Coulomb failure mechanism in which the Prandtl (1921) transition zone is eliminated. This effect is compensated by concentrating the shear transfer along the line $A C$, as shown in Figure $1 \mathrm{~b}$. In this way, the line $A C$ can be thought of as an imaginary retaining wall with the active lateral pressure from zone I pushing against the passive resistance from zone III. From equilibrium of the two wedges involved, bearing capacity factors for each component of strength can be obtained. 


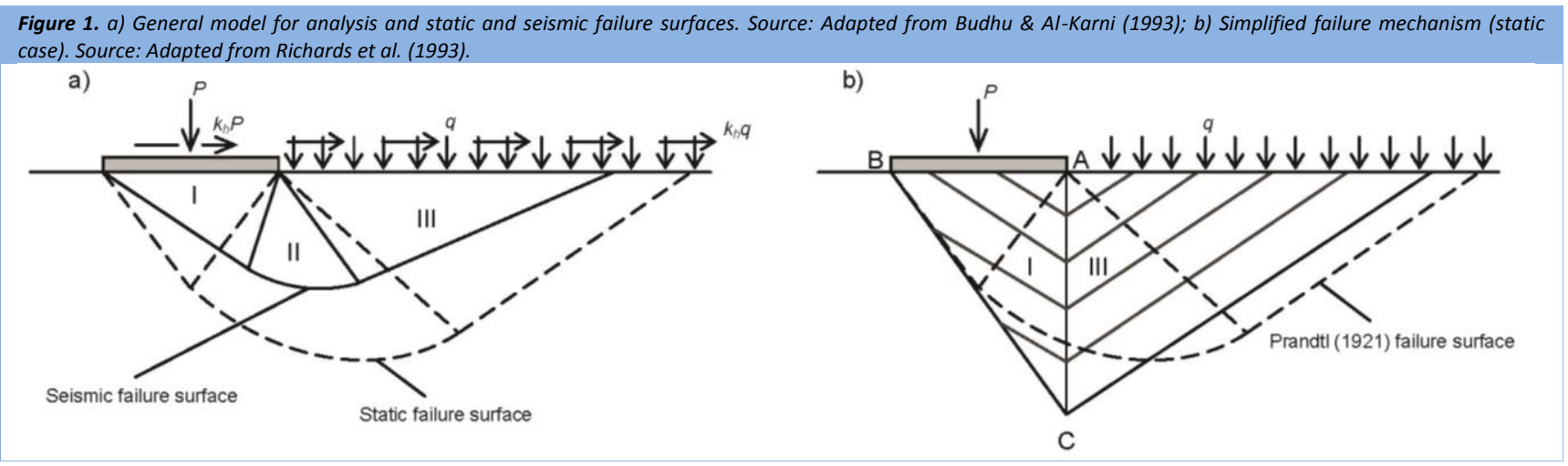

In order to illustrate the influence that seismic loads have on bearing capacity factors, the case of a shallow strip foundation under vertical central loading supported by a soil with $\phi=30^{\circ}$ and no cohesion is considered. Figure 2a shows the variation of the seismic bearing capacity factor $N_{\gamma E}$ with the horizontal seismic coefficient $k_{h}$, according to different methods based on limit equilibrium theory; whereas Figure $2 \mathrm{~b}$ shows the same for different methods based on limit analysis theory. In all cases it is noticed a severe reduction of $N_{Y E}$ factor with increasing acceleration. In general, within methods based on limit analysis theory, it is observed that the method developed by Soubra (1999) gives the best upper-bound solution. It can be also noticed that the solution proposed by Richards et al. (1993), developed in the framework of limit equilibrium theory by considering a simplified failure mechanism, gives results that are in good agreement with those reported by Soubra (1999). The limit equilibrium solutions provided by Budhu \& Al-Karni (1993), Zhu (2000) and Choudhury \& Subba Rao (2005) are those that give the lowest values for the $N_{\gamma E}$ factor. However, as previously mentioned, the relation between these solutions and the exact ones cannot be established beforehand. For this reason these results must to be interpreted cautiously.
On the other side, seismic to static bearing-capacity ratios as function of seismic coefficient $k_{h}$ are shown in Table 1. For this analysis, only the methods proposed by Sarma \& lossifelis (1990), Richards et al. (1993), Budhu \& Al-Karni (1993), Soubra (1999) and Choudhury \& Subba Rao (2005) are considered, because they are aimed to obtain all bearing capacity factors, unlike what happens with the other methods already mentioned, which are focused on the calculation of $N_{\text {曰 }}$ factor. In all cases, it can be observed a rapid decreasing of the seismic to static bearing-capacity ratios with increasing acceleration. Despite the differences between the theories considered, regarding to their assumptions and solution methods, a good agreement is observed between results obtained by using the theories proposed by Sarma \& lossifelis (1990), Soubra (1999), and Richards et al. (1993), with the exception of the case of ratio $N_{c E} / N_{c S}$. This difference is due to the way in which Richards et al. (1993) have obtained the factor $N_{c E}$. In fact, they have used the relation $N_{c E}=\left(N_{q E}-1\right)$ $\cot \phi$ without any real justification (Richards et al., 1993; Soubra, 1999). On the other hand, the theories developed by Budhu \& Al-Karni (1993) and Choudhury \& Subba Rao (2005) are those that give the lowest seismic to static bearingcapacity ratios. However, this latter method predicts a particularly dramatic reduction in the values of all the bearing capacity factors, even for low to moderate $k_{h}$ values.

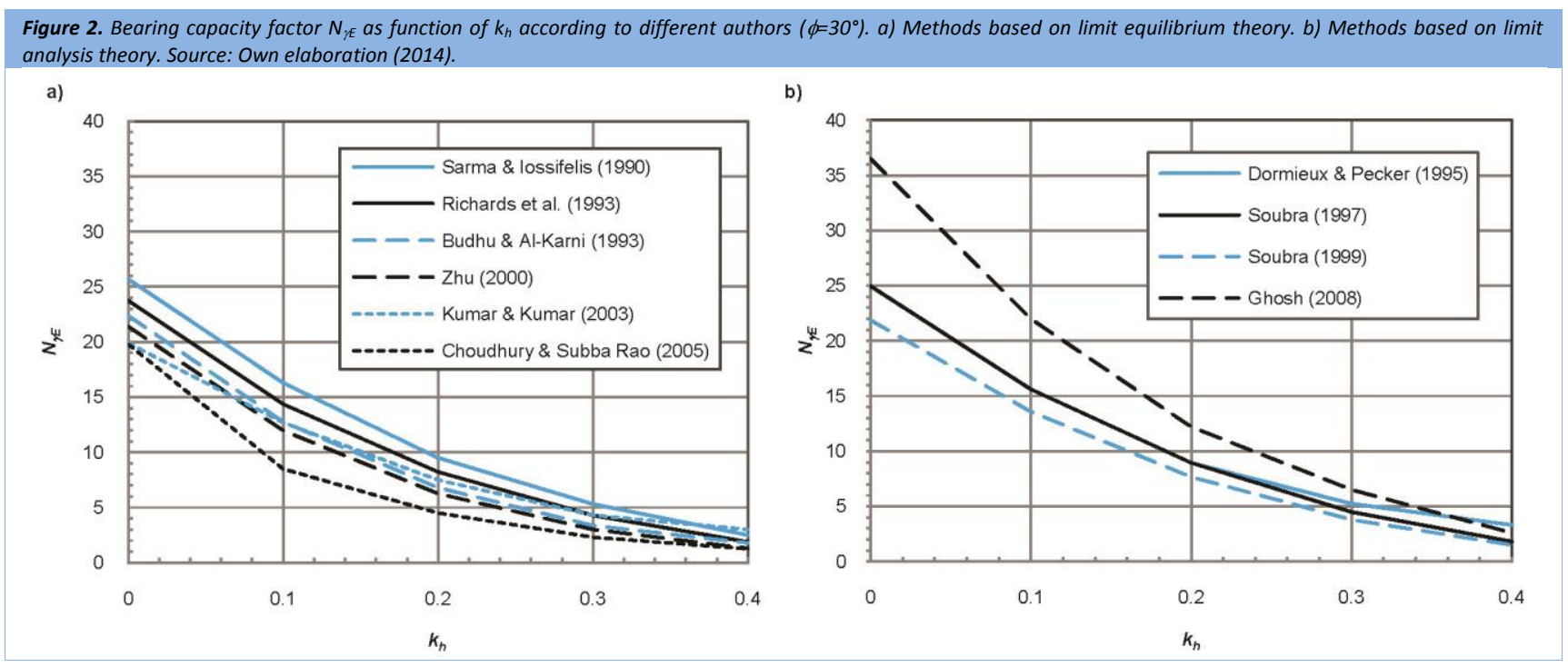




\begin{tabular}{|c|c|c|c|c|c|c|c|c|c|c|c|c|c|c|c|}
\hline \multirow[b]{2}{*}{$k_{h}$} & \multicolumn{3}{|c|}{$\begin{array}{l}\text { Sarma \& lossifelis } \\
\text { (1990) }\end{array}$} & \multicolumn{3}{|c|}{$\begin{array}{l}\text { Richards et al. } \\
\text { (1993) }\end{array}$} & \multicolumn{3}{|c|}{$\begin{array}{l}\text { Budhu \& Al-Karni } \\
\text { (1993) }\end{array}$} & \multicolumn{3}{|c|}{$\begin{array}{l}\text { Soubra } \\
\text { (1999) }\end{array}$} & \multicolumn{3}{|c|}{$\begin{array}{l}\text { Choudhury \& Subba Rao } \\
\text { (2005) }\end{array}$} \\
\hline & $N_{c}$ & $N_{q}$ & $N_{\gamma}$ & $N_{c}$ & $N_{q}$ & $N_{\gamma}$ & $N_{c}$ & $N_{q}$ & $N_{\gamma}$ & $N_{c}$ & $N_{q}$ & $N_{\gamma}$ & $N_{c}$ & $N_{q}$ & $N_{\gamma}$ \\
\hline 0.0 & 1.00 & 1.00 & 1.00 & 1.00 & 1.00 & 1.00 & 1.00 & 1.00 & 1.00 & 1.00 & 1.00 & 1.00 & 1.00 & 1.00 & 1.00 \\
\hline 0.1 & 0.82 & 0.77 & 0.63 & 0.73 & 0.75 & 0.60 & 0.65 & 0.72 & 0.57 & 0.83 & 0.78 & 0.62 & 0.60 & 0.65 & 0.43 \\
\hline 0.2 & 0.67 & 0.58 & 0.37 & 0.52 & 0.55 & 0.35 & 0.42 & 0.49 & 0.29 & 0.67 & 0.58 & 0.35 & 0.37 & 0.41 & 0.23 \\
\hline 0.3 & 0.54 & 0.42 & 0.21 & 0.36 & 0.40 & 0.18 & 0.28 & 0.30 & 0.15 & 0.53 & 0.41 & 0.17 & 0.22 & 0.19 & 0.12 \\
\hline 0.4 & 0.43 & 0.28 & 0.10 & 0.22 & 0.27 & 0.08 & 0.18 & 0.18 & 0.08 & 0.42 & 0.27 & 0.07 & 0.13 & 0.11 & 0.06 \\
\hline
\end{tabular}

\section{Methodology}

The influence that seismic loads have on the reduction of bearing capacity factors highlights the need to obtain a measure of the reliability associated with both calculation methods and safety factors commonly used in practice for seismic design. In the present study, a parametric comparative analysis of different methods for estimating seismic bearing capacity of foundations was carried out. Shallow strip foundations under vertical central loading were considered. Different seismic coefficients $k_{h}$, embedment depths $D$, and soil properties (unit weight $\gamma$, angle of internal friction $\phi$, and cohesion $c$ ) were adopted. Table 2 shows the parameters used in the analysis with their respective ranges of variation.

Table 2. Parameters considered for analysis. Source: Own elaboration (2014).

\begin{tabular}{c|c|c|c|c|c}
\hline$B(\mathrm{~m})$ & $D / B$ & $\gamma\left(\mathrm{kN} / \mathrm{m}^{3}\right)$ & $c(\mathrm{kPa})$ & $\phi(\mathrm{deg})$ & $k_{h}$ \\
\hline 1.0 & 0.5 to 1.5 & 16 to 20 & 0 to 15 & 30 to 45 & 0.1 to 0.3 \\
\hline
\end{tabular}

In order to have a measure of the reliability associated with the practice consisting in estimating seismic bearing capacity through an increase of $33 \%$ in static allowable soil pressures, a reliability index $(R I)$ called $R I_{1}$ is defined as follows in (Eq. 2)., where $q_{u l t E}$ is the ultimate seismic bearing capacity of soil, obtained by using different analytical methods, and $q_{\text {alls }}$ is the respective static allowable bearing capacity determined by using the method proposed by Meyerhof (1963), considering a factor of safety against failure of soil of 3.0. In a similar way, in order to have a measure of the reliability associated with the practice consisting in estimating seismic bearing capacity through an equivalent pseudo-static approach (general bearing capacity equations), an index called $R I_{2}$ is defined as follows in (Eq. 3)., where $q_{\text {ultE }}$ was defined previously and $q_{\text {allM }}$ correspond to the allowable bearing capacity determined by using the method proposed by Meyerhof (1963), considering a factor of safety against failure of soil of 2.0. In this latter calculation, the effect of seismic loads is included by the use of load inclination factors in bearing capacity equations, in addition to the typical shape and depth factors.

$$
\begin{aligned}
& R I_{1}=\frac{q_{\text {ultE }}}{1.33 \times q_{\text {alls }}} \\
& R I_{2}=\frac{q_{\text {ultE }}}{q_{\text {allM }}}
\end{aligned}
$$

With respect to the analytical methods used for the seismic bearing capacity calculations, those proposed by Richards et al. (1993), Budhu \& Al-Karni (1993), and Soubra (1999) were used. These methods are considered to be representative of both limit equilibrium and limit analysis theories and also cover a wide range of the values of bearing capacity factors. Thus, three $R l_{1}$ indexes and three $R I_{2}$ indexes were obtained for each set of parameters considered, which allows assessing the variability of the results and also the sensitivity of each method due to the parameters variations.

\section{Results}

In an illustrative way and, for the sake of brevity, Figure 3 shows the results obtained from the analysis of a shallow strip foundation with $B=1.0 \mathrm{~m}$, supported by a soil with $\gamma=17 \mathrm{kN} / \mathrm{m}^{3}, \phi=35^{\circ}$ and no cohesion $(c=0)$. Three sub-cases were considered ( $a, b$ and $c$ respectively), with embedment ratios $D / B$ of $0.5,1.0$ and 1.5 . It can be noticed that practically in all cases, taking as a reference the method proposed by Budhu \& Al-Karni (1993), values of $R I_{1}$ below to 1.0 are obtained, which imply that the traditional approaches for estimating seismic bearing capacity of foundations could be unsafe. However, very different results are obtained when theories proposed by Richards et al. (1993) and Soubra (1999) are taken as a reference. In this way, in relation to the $R I_{1}$ index, it is observed that for seismic coefficients below 0.2 , reliability indexes greater than 1.0 are obtained, reaching values up to 1.60 for $k_{h}=0.1$. Nevertheless, it is noted that for $k_{h}>0.2$ the results show that the practice consisting in estimating seismic bearing capacity through an increase of $33 \%$ in static allowable soil pressures could be on the unsafe side. In addition, the increase in embedment depth not implies significant improvements on the reliability indexes.

On the other hand, it is observed that the $R I_{2}$ index is always greater than the $R I_{1}$ index, showing values above 1.0 for all cases considered, and up to 2.0 in the case of moderate earthquakes. Moreover, it can be noted that as the embedment depth increases, the reliability associated with the practice consisting in estimating seismic bearing capacity through the general bearing capacity equations proposed by Meyerhof (1963) decreases with respect to the results given by the analytical methods.

On the other side, Figure 4 shows the results obtained from the analysis of a shallow strip foundation with $B=1.0 \mathrm{~m}$, supported by a soil with $\gamma=20 \mathrm{kN} / \mathrm{m}^{3}, \phi=45^{\circ}$ and an embedment ratio $D / B$ of 0.5 . Three sub-cases were considered ( $a, b$ and $c$ respectively), with cohesion values (in $\mathrm{kPa}$ ) of $0,7.5$ and 15. From the results obtained, it can be noted that the method proposed by Budhu \& Al-Karni (1993) is particularly sensitive to the inclusion of cohesion as a 
resistance parameter, mainly for the case of moderate earthquakes in which both $R I_{1}$ and $R I_{2}$ indexes increases considerably. However, it is possible to see that according to this theory the traditional approaches for estimating seismic bearing capacity of foundations could be unsafe practically in all cases. In relation with the reliability values obtained taking as a reference the theories proposed by Richards et al. (1993) and Soubra (1999), a similar tendency to the results shown in Figure 3 is observed. The use of an increasing factor of 1.33 for the static allowable pressures calculated by the method proposed by Meyerhof (1963) in order to estimating the seismic bearing capacity, gives results for the reliability index $R I_{1}$ that could be less than 1.0 for earthquakes represented by seismic coefficients above 0.17 .

Instead, the index $R I_{2}$ is always greater than 1.0, for all seismic coefficients considered. Finally, it can be seen that as both cohesion and seismic coefficient increases, the results obtained with respect to each analytical method differ increasingly. This is due to the way the different authors obtain the seismic bearing capacity factor $N_{C E}$, which affects the way the ratio $N_{C E} / N_{C S}$ is reduced (Table 1 ).
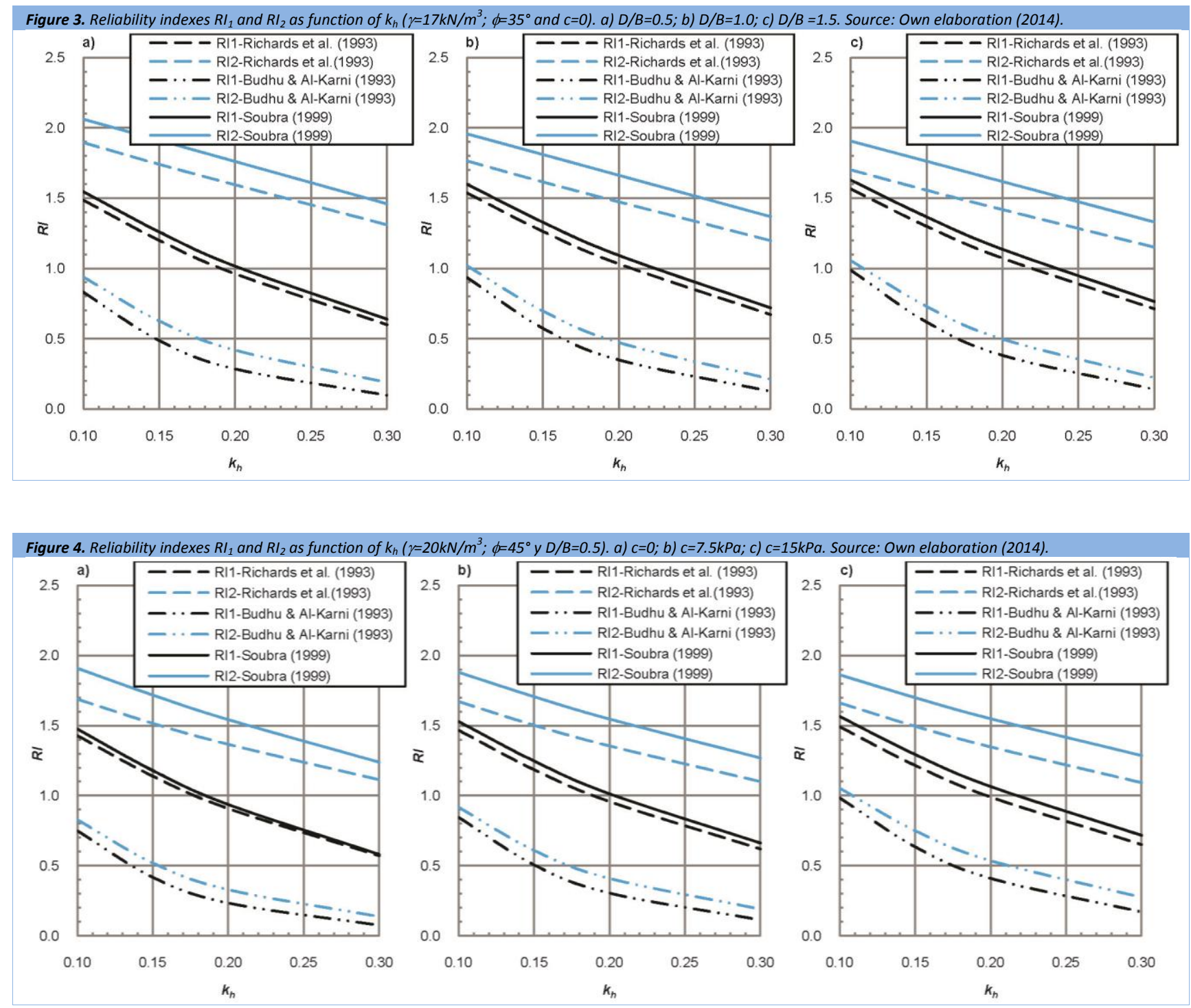

\section{Discussion}

The results shown above must to be interpreted in light of available evidence in earthquakes. Generally speaking, foundations may experience a reduction in bearing capacity and increase in settlement and tilt due to seismic loading. This may happen due to cyclic degradation of soil resistance properties during the earthquake, the generation of soil pore pressures at the end of the earthquake, or due to the occurrence of liquefaction, among other reasons. In this sense, although foundation failures only due to problems associated with bearing capacity has been observed, for example, during the 1971 San Fernando earthquake in the United States (Whitman \& Bielak, 1980) or the 1978
Miyagihen-Oki earthquake in Japan (Okamoto, 1978), most of failures of foundations during earthquakes are related to the occurrence of liquefaction (Richards et al., 1993; Kramer, 1996; Bray \& Dashti, 2012). In this way, for instance, during the 27 February 2010 Maule earthquake $\left(M_{w}=8.8\right)$ in Chile, a series of buildings and critical lifeline structures such as ports, bridges, industrial facilities, railroads and roadway embankments were strongly damaged due to this phenomenon (Bray et al., 2012; Ledezma et al., 2012; Assimaki et al., 2012), which was the most commonly observed mode of failure. For this reason, the reliability indexes $R I_{1}$ and $R I_{2}$ obtained taking as a reference the theory developed by Budhu \& Al-Karni (1993) are particularly 
noteworthy, since they are contradictory with respect to the behavior of foundations observed during major earthquakes.

On the other hand, whereas the practice consisting in estimating seismic bearing capacity through an equivalent pseudo-static approach by using the equations proposed by Meyerhof (1963) gives values for the reliability indexes that are in good agreement with experimental evidence, it is observed that, for high seismic coefficients, the use of the practice consisting in estimating seismic bearing capacity through an increase of $33 \%$ in static allowable soil pressures could be unsafe. This necessarily leads to the question about the pertinence of the use of such increasing percentage.
Figure 5 shows how reliability indexes presented in Figure 3 vary when no increasing on static allowable soil pressures is considered, whereas Figure 6 shows the same in relation with the results shown in Figure 4. For these analyses, an index $R I_{3}$ is defined as (Eq. 4).

$$
R I_{3}=\frac{q_{u l t E}}{q_{a l l S}}
$$
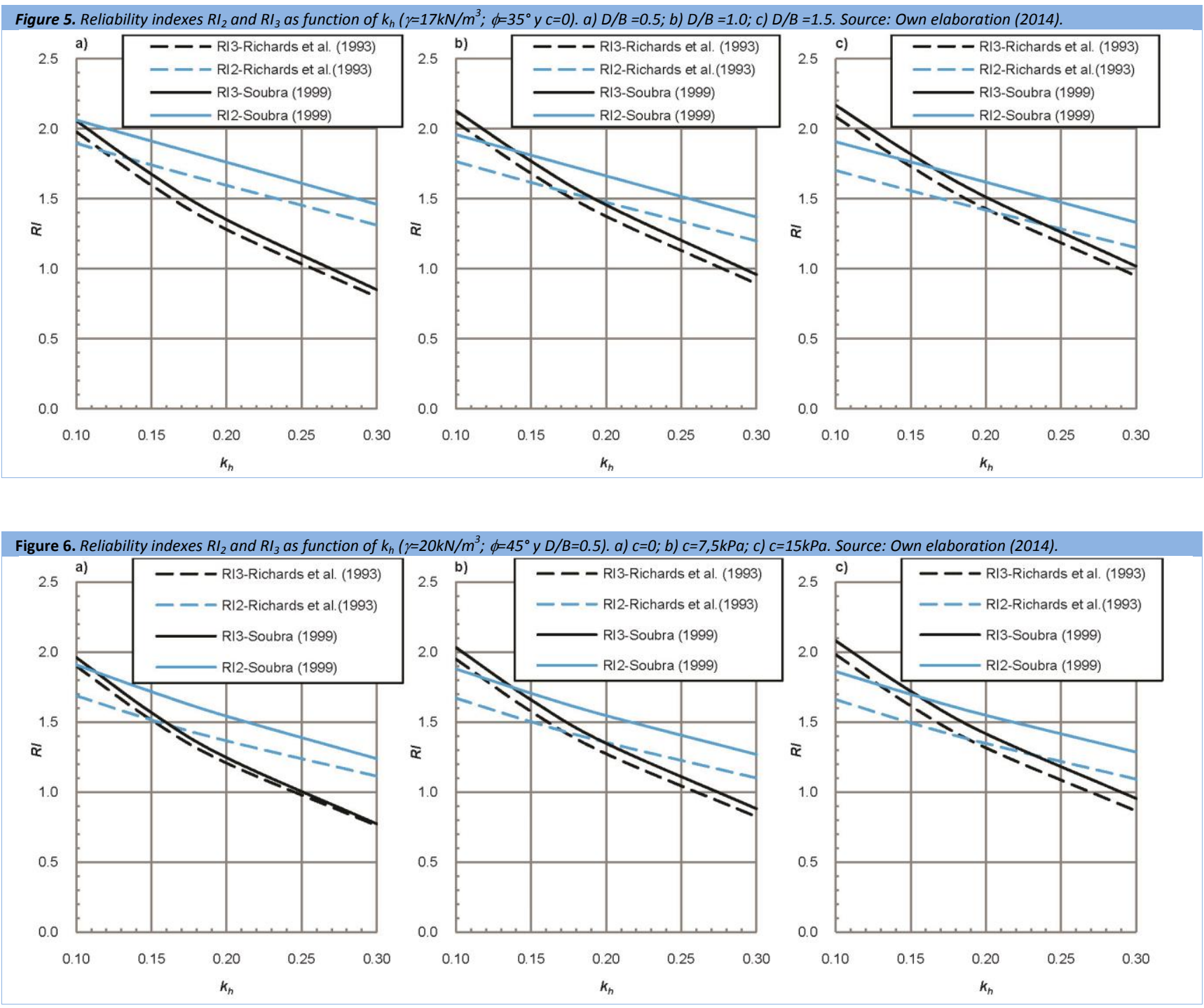

It can be noted that although $R l_{3}$ values increases to levels similar to those obtained for $R I_{2}$ in the case of moderate seismic coefficients, as $k_{h}$ increases, the practice associated to the use of an equivalent pseudo-static approach still providing greater reliability with respect to the ultimate seismic load predicted by the analytical methods considered.

Finally, a key aspect for evaluating the reliability given by the existing approximate design methods is related to the choice of $k_{h}$. Typically, when pseudo-static analyses are used, seismic coefficients expressed as a percentage of the expected maximum ground acceleration $\left(a_{\max }\right)$ at the zone of interest (in this case, on the foundation level) are utilized (Sanhueza \& Villavicencio, 2012). In general, the percentages used vary from $33 \%$ to $50 \%$ (Kramer, 1996). In particular, in Chile, in absence of a seismic risk study that allows to properly determine the value of $a_{\max }$, for design purposes, the Highway Manual of the Ministry of Public Works (MOP Highway Manual, 2012) suggest to consider $k_{h}=0.5 A^{\prime} / g$, where $A_{O}$ is the maximum effective acceleration defined by the standard NCh433: 1996 Mod. 2009 according to the seismic zones of the country (INN NCh433:1996 Mod. 2009, 2009). Otherwise, the following expressions developed by Saragoni (1993) can be used (Eq. 5). These two alternatives 
give values of $k_{h}$ that can vary, typically, from 0.10 to 0.22 , which allows to determine ranges of applicability of the presented methods and also giving recommendations for design purposes.

$$
k_{h}= \begin{cases}0.30 a_{\text {max }} / g, & \text { if } a_{\text {max }} \leq 0.67 g \\ 0.22\left(a_{\max } / g\right)^{0.33,}, & \text { if } a_{\text {max }}>0.67 g\end{cases}
$$

\section{Acknowledgements}

The authors thank Universidad Andres Bello for the support given during the development of this work.
Conclusions

This paper presents an analysis of the seismic bearing capacity of shallow strip foundations. Through a parametric study, the reliability associated to the traditional procedures for estimating the mentioned bearing capacity with respect to the results given by available analytical methods developed in the framework of both limit equilibrium and limit analysis theories was evaluated. From the results obtained, the following conclusions can be addressed:

In the opinion of the authors, the method proposed by Budhu \& Al-Karni (1993) should not be used for estimating seismic bearing capacity of shallow strip foundations, since it gives results that are contradictory with respect to the behavior of foundations observed during major earthquakes, in both Chile and the rest of world.

In general terms, it was found that the theories proposed by Richards et al. (1993) and Soubra (1999) give results that are in good agreement with the available experimental evidence. Thus, it is possible to recommend its use for practical purposes, preferring the first of them because its simplicity regarding both formulation and application.

In relation with the practice consisting in estimating seismic bearing capacity through an equivalent pseudo-static approach by using the general bearing capacity equations, as proposed for example by Meyerhof (1963), it was found that its use is reliable compared with the ultimate load predicted by the analytical methods for all seismic coefficients considered in the analysis. However, the values obtained for $R I_{2}$ index shown that as $k_{h}$ increases, reliability decreases from values about 2.0 to 1.30 approximately for the seismic coefficients typically used in Chile. Although these values are considered satisfactory from a theoretical point of view, they are less than the safety factors commonly used in geotechnical engineering for design of foundations under seismic or dynamic loads.

Finally, in relation with the practice consisting in estimating seismic bearing capacity through an increase of $33 \%$ in static allowable soil pressures, it was found that its use may lead, mainly for seismic coefficients greater than 0.20 , to results on the unsafe side. For this reason, it is recommended to review the adequacy of this practice and avoid the use of increasing percentages greater than 33\%, especially for the case of foundations on granular soils, due to its vulnerability to seismic densification. 


\section{References}

AASHTO HB-17 (2002). American Association of State Highway and Transportation Officials. Standard Specifications for Highway Bridges (17th ed.). American Association of State Highway and Transportation Officials: Washington, D.C., United States.

Assimaki, D., Ledezma, C., Montalva, G. A., Tassara, A., Mylonakis, G., \& Boroschek, R. (2012). Site effects and damage patterns. Earthquake Spectra, 28(S1), 55-74.

ASTM D1194-72 (1987). American Society for Testing and Materials. Standard Test Methods for Bearing Capacity of Soil for Static Load and Spread Footings. American Society for Testing and Materials: Pasadena, United States.

Bowles, J. E. (1996). Foundation analysis and design (5th ed.). New York: McGraw-Hill.

Bray, J., Rollins, K., Hutchinson, T., Verdugo, R., Ledezma, C., Mylonakis, G. Assimaki, D., Montalva, G., Arduino, P., Olson, S.M., Kayen, R., Hashash, Y., \& Candia, G. (2012). Effects of ground failure on buildings, ports, and industrial facilities. Earthquake Spectra, 28(S1), 97-118.

Bray, J.D. \& Dashti, S. (2012). Liquefaction-Induced building movements. 2nd International Conference on Performance-Based Design Earthquake Geotechnical Engineering, Taormina.

Budhu, M., \& Al-Karni, A. (1993). Seismic bearing capacity of soils. Géotechnique, 43(1), 181-187.

Caquot, A., \& Kerisel, J. (1953). Ultimate Bearing Capacity of a Foundation Lying on the Surface of a Cohesionless Soil (in French). 3rd International Conference on Soil Mechanics and Foundation Engineering, Zürich.

Castelli, F., \& Motta, E. (2010). Bearing capacity of strip footings near slopes. Geotechnical and Geological Engineering, 28(2), 187-198.

CEN Eurocode 8 (2004). European Committee for Standardization. Design of Structures for Earthquake Resistance-Part 5: Foundations, Retaining Structures and Geotechnical Aspects. European Committee for Standardization: Brussels, Belgium.

Chen, W. F., \& Scawthorn, C. R. (1970). Limit analysis and limit equilibrium solutions in soil mechanics. Soils and Foundations, 10(3), 13-49.

Chen, W. F. (1975). Limit analysis and soil plasticity. Amsterdam: Elsevier.

Choudhury, D., \& Subba Rao, K. S. (2005). Seismic bearing capacity of shallow strip footings. Geotechnical and Geological Engineering, 23(4), 403-418.

Choudhury, D., \& Subba Rao, K. S. (2006). Seismic bearing capacity of shallow strip footings embedded in slope. International Journal of Geomechanics, 6(3), 176-184.

Day, R. (2006). Foundation engineering handbook: design and construction with the 2006 international building code. New York: McGraw-Hill.

Dormieux, L., \& Pecker, A. (1995). Seismic bearing capacity of foundation on cohesionless soil. Journal of Geotechnical Engineering, 121(3), 300-303.
Farzaneh, O., Mofidi, J. \& Askari, F. (2013). Seismic Bearing Capacity of Strip Footings Near Cohesive Slopes Using Lower Bound Limit Analysis. 18th International Conference on Soil Mechanics and Geotechnical Engineering, Paris.

Ghosh, P. (2008). Upper bound solutions of bearing capacity of strip footing by pseudo-dynamic approach. Acta Geotechnica, 3(2), 115-123.

Hansen, J.B. (1970). A revised and extended formula for bearing capacity. Geoteknisk Inst., Bulletin 28, 5-11.

ICC IBC (2012). International Code Council. International Building Code. International Code Council: Washington D.C., United States.

INN NCh433:1996 Mod. 2009 (2009). National Institute of Normalization. Earthquake-resistant design of buildings (in Spanish). National Institute of Normalization: Santiago, Chile.

INN NCh2369:2003 (2003). National Institute of Normalization. Earthquake-resistant design of industrial structures and facilities (in Spanish). National Institute of Normalization: Santiago, Chile.

Kramer, S. L. (1996). Geotechnical earthquake engineering. Upper Saddle River, NJ.: Prentice Hall.

Kumar, J., \& Kumar, N. (2003). Seismic bearing capacity of rough footings on slopes using limit equilibrium. Géotechnique, 53(3), 363-369.

Lam, I. P., \& Martin, G. R. (1986). Seismic design of highway bridge foundations (Reports FHWA/RD-86/101, 102 and 103). Washington, D.C.: Federal Highway Administration.

Ledezma, C., Hutchinson, T., Ashford, S. A., Moss, R., Arduino, P., Bray, J. D., Olson, S., Hashash, Y., Verdugo, R., Frost, D., Kayen, R., \& Rollins, K. (2012). Effects of ground failure on bridges, roads, and railroads. Earthquake Spectra, 28(S1), S119-S143.

Lee, J., \& Salgado, R. (2005). Estimation of bearing capacity of circular footings on sands based on cone penetration test. Journal of Geotechnical and Geoenvironmental Engineering, 131(4), 442-452.

Meyerhof, G. G. (1951). The ultimate bearing capacity of foundations. Géotechnique, 2(4), 301-332.

Meyerhof, G. T. (1953). The Bearing Capacity of Foundations Under Eccentric and Inclined Loads. 3rd International Conference on Soil Mechanics, Zurich.

Meyerhof, G. G. (1963). Some recent research on the bearing capacity of foundations. Canadian Geotechnical Journal, 1(1), 16-26.

MOP Highway Manual (2012). Ministry of Public Works. Highway Manual-Vol. 3: Instructions and design criteria (in Spanish). Ministry of Public Works: Santiago, Chile.

Okamoto, S. (1978). Introduction to earthquake engineering. Tokyo: University of Tokio Press.

Paolucci, R., \& Pecker, A. (1997). Seismic bearing capacity of shallow strip foundations on dry soils. Soils and Foundations, 37(3), 95-105.

Peck, R. B., Hanson, W. E., \& Thornburn, T. H. (1974). Foundation engineering $(2 \mathrm{~d}$ ed.) New York: Wiley. 
Prandtl, L. (1921). On the penetrating strengths (hardness) of plastic construction materials and the strength of cutting edges (in German). ZAMM Journal of Applied Mathematics and Mechanics, 1(1), 15-20.

Puri, V., \& Prakash, S. (2007) Foundations for Seismic Loads. Dynamic Response and Soil Properties, 1-10. doi: 10.1061/40904(223)11.

Richards Jr. R., Elms, D. G., \& Budhu, M. (1993). Seismic bearing capacity and settlements of foundations. Journal of Geotechnical Engineering, 119(4), 662-674.

Saada, Z., Maghous, S., \& Garnier, D. (2011). Seismic bearing capacity of shallow foundations near rock slopes using the generalized Hoek-Brown criterion. International Journal for Numerical and Analytical Methods in Geomechanics, 35(6), 724-748.

Sanhueza, C., \& Villavicencio, G. (2012). Influencia de la cohesión aparente generada por raíces sobre la estabilidad de un talud natural en las dunas de Reñaca. Revista de la Construcción, 11(1), 16-31.

Saragoni, R. (1993). Seismic Risk Analysis for the Reconstruction of Valparaíso Port (in Spanish). 6tas Jornadas Chilenas de Sismología e Ingeniería Antisísmica, Santiago.

Sarma, S. K., \& lossifelis, I. S. (1990). Seismic bearing capacity factors of shallow strip footings. Géotechnique, 40(2), 265-273.

Shinohara, T., Tateishi, T. \& Kubo, K. (1960). Bearing Capacity of Sandy Soil for Eccentric and Inclined Load and Lateral Resistance of Single Piles Embedded in Sandy Soil. 2nd World Conference on Earthquake Engineering, Tokyo.

Soubra, A. H. (1997). Seismic bearing capacity of shallow strip footings in seismic conditions. Proceedings of the Institution of Civil Engineers: Geotechnical Engineering, 125 (4), 230-241.

Soubra, A. H. (1999). Upper-bound solutions for bearing capacity of foundations. Journal of Geotechnical and Geoenvironmental Engineering, 125(1), 59-68.

Terzaghi, K. (1943). Theoretical Soil Mechanics. New York: John Wiley \& Sons.

Vesic, A. S. (1973). Analysis of ultimate loads of shallow foundations. Journal of the Soil Mechanics and Foundations Division, 99(sm1), 43-73.

Whitman, R., \& Bielak, J. (1980). Chap. 7: Foundations. Design Earthquake Resistant Structures. London: Pentech Press.

Yang, X. L. (2009). Seismic bearing capacity of a strip footing on rock slopes. Canadian Geotechnical Journal, 46(8), 943-954.

Zhu, D. (2000). The least upper-bound solutions for bearing capacity factor $\mathrm{N}_{\gamma}$. Soils and Foundations, 40(1), 123-129. 